\title{
EFFECT OF AMIODARONE ON RABBITS' OPTIC NERVE AND THE AMELIORATIVE EFFECT OF VITAMIN E: FTIR STUDY
}

\author{
EMAN M. A. ${ }^{1}$, SHERIF S. M. ${ }^{2}$, SAHAR A. M. ${ }^{3}$, AHLAM M. I. ${ }^{4}$, GEHAN M. K. ${ }^{5}$
}

${ }^{1}$ Head of Biophysics and Laser Science Unit, Visual Science Department, Research Institute of Ophthalmology-Giza, Egypt, ${ }^{2} \mathrm{Head}$ of Visual Science Department, Research Institute of Ophthalmology-Giza, Egypt, ${ }^{3}$ Assistant Lecturer, Physics Department, Faculty of Science (Girls), Al Azhar University, Cairo, Egypt, 4,5 Physics Department, Faculty of Science (Girls), Al Azhar University, Cairo, Egypt Email: em_saleh2014@hotmail.com

Received: 03 Nov 2021, Revised and Accepted: 07 Dec 2021

\section{ABSTRACT}

Objective: The study aimed to investigate the structural and conformational changes induced by short-term administration of the amiodarone in the optic nerve besides validating whether vitamin E coadministration with amiodarone will improve these changes.

Methods: Thirty New Zealand white rabbits from both sexes were haphazardly categorized into three groups, whereas each group contains ten rabbits (20 eyes). One of these groups served as a control that received an intraperitoneal injection of normal saline. Rabbits in the second group intraperitoneally (ip) injected daily with $160 \mathrm{mg} / \mathrm{kg}$ body weight (bw) of amiodarone for two weeks. The last group orally administration 100 $\mathrm{mg} / \mathrm{kg}$ bw of vitamin $\mathrm{E}$ with the $160 \mathrm{mg} / \mathrm{kg}$ bw of amiodarone ip daily for two weeks until the time of sacrifice. Fourier transform infrared spectroscopy (FTIR) analysis was conducted on the optic nerve of the all groups.

Results: The results obtained from the FTIR spectrum revealed that the short-term administration of amiodarone caused a significant alteration in the stretching $\mathrm{NH}-\mathrm{OH}$ region. A newly detected component centered at $3739 \pm 1 \mathrm{~cm}^{-1}$ was assigned as strO-H. There was a significant decrease $(\mathrm{p}<0.05)$ in the bandwidth and band position of one component of $\mathrm{str} \mathrm{O}-\mathrm{H}$ that centered at $3598 \pm 1 \mathrm{~cm}^{-1}$. Moreover, remaining vibrational bands $(\mathrm{O}$ $\mathrm{H}_{\text {asym }}$ and $\mathrm{O}-\mathrm{H}_{\text {sym }}$ ) were shifted to higher frequencies. Coadministration of vitamin $\mathrm{E}$ with amiodarone reduced the contour to four components as a control with significant increase in the band position of $\mathrm{O}-\mathrm{H}_{\text {asym }}$ and the bandwidth of one component of str $\mathrm{O}$ - $\mathrm{H}$. Amiodarone administrations lead to reducing the area ratio of asym $\mathrm{CH}_{2}$ to sym $\mathrm{CH}_{2}$ and elevation of the area ratio of asym $\mathrm{CH}_{2}$ to asym $\mathrm{CH}_{3}$ while the coadministration of vitamin $\mathrm{E}$ returned it as the control ratio. The percentage of the $\beta$-turn was significantly increased while the $\alpha$-helix content was decreased due to amiodarone. The contents of both components were considered mimicking the control values when Vitamin E was co-administered with amiodarone.

Conclusion: The study stated that amiodarone could change the solubility and folding of the optic nerve proteins. Finally, vitamin E intake with amiodarone turns many of these changes induced by amiodarone to normal levels, which make it a good supplement for amiodarone users.

Keywords: Amiodarone, Optic nerve, FTIR spectroscopy, Lipid, Protein, Antiarrhythmic drug, Rabbits, Vitamin E

(C) 2022 The Authors. Published by Innovare Academic Sciences Pvt Ltd. This is an open-access article under the CC BY license (https://creativecommons.org/licenses/by/4.0/] DOI: https://dx.doi.org/10.22159/ijap.2022v14i1.43507. Journal homepage: https://innovareacademics.in/journals/index.php/ijap

\section{INTRODUCTION}

Ventricular arrhythmias (abnormal heart rhythms) are considered the leading causes of sudden cardiac death [1], so numerous antiarrhythmic drugs have been applied to treatment. Amiodarone is a potent antiarrhythmic drug that has been operating for the treatment of various types of tachyarrhythmias [2]. It was incorporate in 1960 as a potent coronary vasodilator for treating symptoms of angina. The antiarrhythmic properties were recorded in 1969; after that, the United States Food and Drug Administration (USFDA) licensed the drug to treat ventricular arrhythmias in 1985. Since this time, it has been used worldwide to treat numerous ventricular cardiac rhythm disturbances [3]. The amiodarone antiarrhythmic properties come from various mechanisms, including repolarization elongation, slowing the conduction of stimuli, and decreased excitability [4].

Amiodarone has been linked to several adverse side effects despite its highly beneficial effects in treating many kinds of tachyarrhythmias. Because of the harmful effects of amiodarone, the percentage of patients stopping to take the medication in the first year was about $23 \%$, besides approximately half of the long-term users eventually stop using the medicine [5, 6]. These adverse amiodarone effects have been connected to the drug's dose, duration of administration, and the long elimination half-life. The toxicity of amiodarone is ubiquitous and affects the lungs [7], liver [8], kidneys [9], thyroid [10], skin [11] and ocular system [12]. It also induces oxidative stress by increasing mitochondrial $\mathrm{H}_{2} \mathrm{O}_{2}$ synthesis and reducing the hepatic ATP content [13]. There are numerous case reports describe optic neuropathy related to amiodarone medication [14-17]. Medication with amiodarone was found to induce degenerative effects on the optic nerve [5]. It was pointed out the risk of developing optic neuropathy has two fold elevated in patients receiving amiodarone, especially in males, and also due to long duration of amiodarone uptake [18].

Vitamin E is regarded as a potent antioxidant because it can be scavenges lipid peroxyl radicals by contributing hydrogen from its phenolic group on the chromanol ring [19]. Ágoston et al. (2003) [20] demonstrated that when vitamin E is coadministered with amiodarone it can penetrate cells and reduced lysosomal phospholipidosis induced by amiodarone. In the same context, Zidan (2011) [7] stated that the uptake of vitamin E concomitant with amiodarone reduces the amiodarone's lung injury while; ultrastructure examination of rat's liver received amiodarone and vitamin E manifested lesser depositions of phospholipids in liver cell organelles and lesser damage in the nucleus than received amiodarone alone [21].

Because of studies reporting the side effect of amiodarone on the optic nerve are limited, this study aimed to investigate the structural and conformational changes induced by short-term administration of the amiodarone in the optic nerve besides validating whether vitamin $\mathrm{E}$ coadministration with amiodarone will improve these changes.

\section{MATERIALS AND METHODS}

\section{Chemicals}

Amiodarone hydrochloride (Cordarone ${ }^{\circledR}, 200 \mathrm{mg}$ ) was purchased from a commercial company (Global Napi Pharmaceuticals, Cairo, Egypt). Vitamin E (400 mg) was purchased from Pharco Pharmaceuticals Company, Cairo, Egypt, and the other chemicals were purchased from Sigma Aldrich (St. Louis, MO, USA) with the highest purity. 


\section{Animals}

Thirty healthy New Zealand white rabbits from both sexes (2-2.5 kg) were randomly selected from the animal house facility at the Research Institute of Ophthalmology, Giza, Egypt. The local ethical committee approved the experiment's protocol according to the guidelines of The Association for Research in Vision and Ophthalmology (ARVO) with approval number 103/2018. Animals were housed separately under appropriate ventilation and an adequate standard diet. They were housed in stainless metallic cages and maintained under constant airflow and illumination during the experimental periods (temperature: $25 \pm 2{ }^{\circ} \mathrm{C}$; light intensity: 300 $400 \mathrm{~lx}$ and $12 \mathrm{~h}$ light/dark cycle), also away from any acoustic stress.

\section{Experimental design}

Rabbits were divided into three groups (10 each, 20 eyes) as follows: the first group was served as the control group and received an intraperitoneal injection of normal saline $(2 \mathrm{ml} / \mathrm{rabbit})$. The second group was intraperitoneally injected with a daily dose of $160 \mathrm{mg} / \mathrm{kg}$ body weight (bw) of amiodarone (2 ml/rabbit) for two weeks [22]. The third group was orally administrated $100 \mathrm{mg} / \mathrm{kg}$ bw of vitamin E [7] and $160 \mathrm{mg} / \mathrm{kg}$ bw of amiodarone ( $2 \mathrm{ml} / \mathrm{rabbit}$ ) intraperitoneally daily for two weeks as the second group. At the end of the administration period, rabbits were sacrificed by decapitation, and their eyes were enucleated; then, the optic nerve was dissected and submerged in liquid nitrogen then crushed to powder.

\section{Sample preparation and FTIR technique}

To record the infrared absorption spectrum, $\mathrm{KBr}$ disks were prepared by mixing $5 \mathrm{mg}$ of optic nerve powder with $95 \mathrm{mg} \mathrm{KBr}$ powder and pressed to form a transparent disk. FTIR measurements were taken using an infrared spectrophotometer model Nicolet is5 (Thermo Fisher Scientific Inc. USA) with an effective resolution of 2 $\mathrm{cm}^{-1}$. Spectra were collected under a continuous flow of nitrogen gas to avoid the impact of ambient $\mathrm{CO}_{2}$ and $\mathrm{H}_{2} \mathrm{O}$ vapor on the results. Typically, each sample has one hundred interferograms. SavitskyGolay smooth function (11 points) was used to smooth the spectra to eliminate noise. Individual spectra from each sample of the same group were averaged to obtain the final group spectrum by using OriginPro 2016 (64-bit) software package (OriginLab Corporation, Northampton, MA 01060, USA). This group spectrum was normalized and analyzed using the same software [23].

\section{Statistical analysis}

Results were displayed as the mean \pm SD. To compare groups, oneway ANOVA was performed by using a commercially available software program (SPSS-11 for windows, SPSS Inc., Chicago, IL, USA), where the significance level was set at $\mathrm{p}<0.05$.

\section{RESULTS}

Fig. 1 shows the infrared absorption spectra of the control, amiodarone treated and Amiodarne+Vitamine $\mathrm{E}$ covers the frequency range $4000-900 \mathrm{~cm}^{-1}$. The main manifested feature of the spectra is that treatment with Amiodarone resulted in an increase in the intensity of the spectra compared to the control. On the other hand, coadministration of vitamin E accompanied amiodarone was associated with reduced absorption intensity relative to either the control group or Amiodarone one.

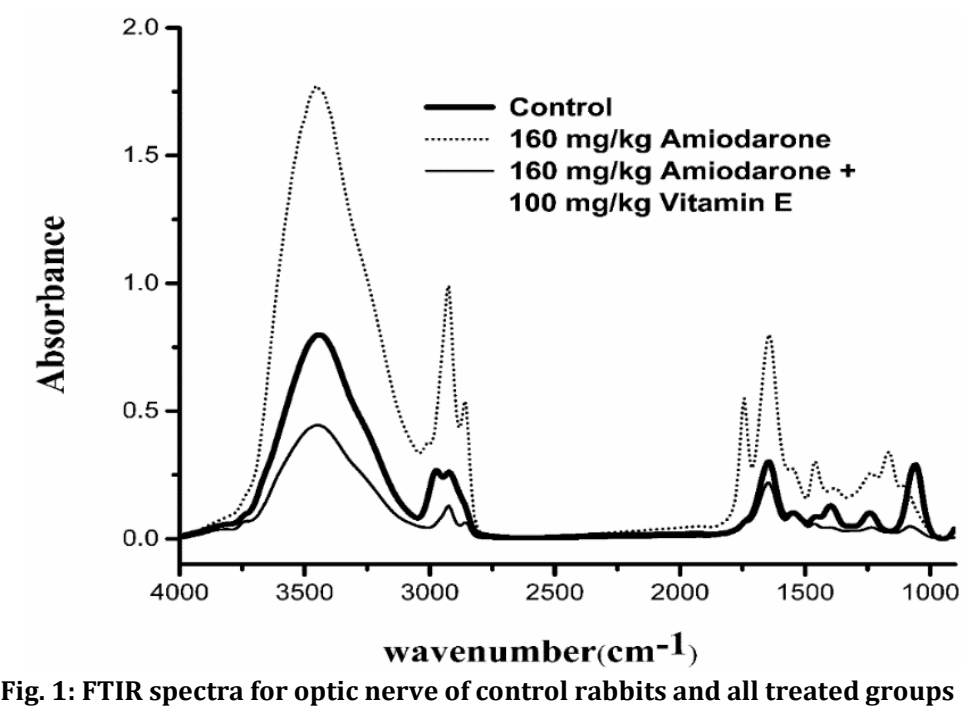

Proteins, lipids, carbohydrates, and nucleic acids are the principal molecules that make up biological samples. Because each of these tissue components has its distinct vibrational fingerprint, the organic molecules in the tissue produce an infrared spectrum with intricately overlapping absorption bands. To resolve this overlapping, spectral analysis, normalization, deconvolution, and curve fitting, were made for all spectra in three frequency ranges: $4000-3000 \mathrm{~cm}^{-1}$ (NH-OH region), $3000-2800 \mathrm{~cm}^{-1}(\mathrm{CH}$ stretching region), and 1800-900 $\mathrm{cm}^{-1}$ (fingerprint region). Amide I (1700$1600 \mathrm{~cm}^{-1}$ ), which refers to the fingerprint region, was discussed separately because of its importance in studying protein secondary structure.

\section{NHOH region}

Fig. 2 shows the stretching $\mathrm{NH}-\mathrm{OH}$ region of control and treated groups in the frequency range $4000-3000 \mathrm{~cm}^{-1}$. The curve enhancement procedure decomposed the contour of the control group into four structural components, which were centered at $3837 \pm 1,3598 \pm 1 \mathrm{~cm}^{-1}$ and assigned as stretching $\mathrm{OH}(\mathrm{str} \mathrm{O}-\mathrm{H}), 3435 \pm 2$ $\mathrm{cm}^{-1}$ (asymmetric $\mathrm{OH}, 0-\mathrm{H}_{\text {asym }}$ ), and finally, $3238 \pm 5 \mathrm{~cm}^{-1}$ which assigned as symmetric $\mathrm{OH}\left(\mathrm{O}-\mathrm{H}_{\text {sym }}\right)$. These assignments listed in the table 1 were based on Dovbeshko et al. [24]. Owing to amiodarone administration: A newly detected component centered at $3739 \pm 1$ $\mathrm{cm}^{-1}$ was assigned as ${ }_{\mathrm{str}} \mathrm{O}-\mathrm{H}$. There was a significant decrease $(\mathrm{p}<0.05)$ in the bandwidth and band position of one component of ${ }_{\text {str }} \mathrm{O}-\mathrm{H}$ that centered at $3598 \pm 1 \mathrm{~cm}^{-1}$. Moreover, the remaining vibrational bands $\left(\mathrm{O}-\mathrm{H}_{\mathrm{asym}}\right.$ and $\left.\mathrm{O}-\mathrm{H}_{\text {sym }}\right)$ were shifted to higher frequencies. In addition, the bandwidth of $\mathrm{O}-\mathrm{H}_{\text {asym }}$ was decreased while; increased in the $0-\mathrm{H}_{\text {sym }}$ mode.

Co-administration of vitamin $\mathrm{E}$ with amiodarone reduced the contour to four components as control with the significant increase in the band position of $\mathrm{O}-\mathrm{H}_{\text {asym }}$ and the bandwidth of one component of $_{\text {str }} \mathrm{O}-\mathrm{H}$. 


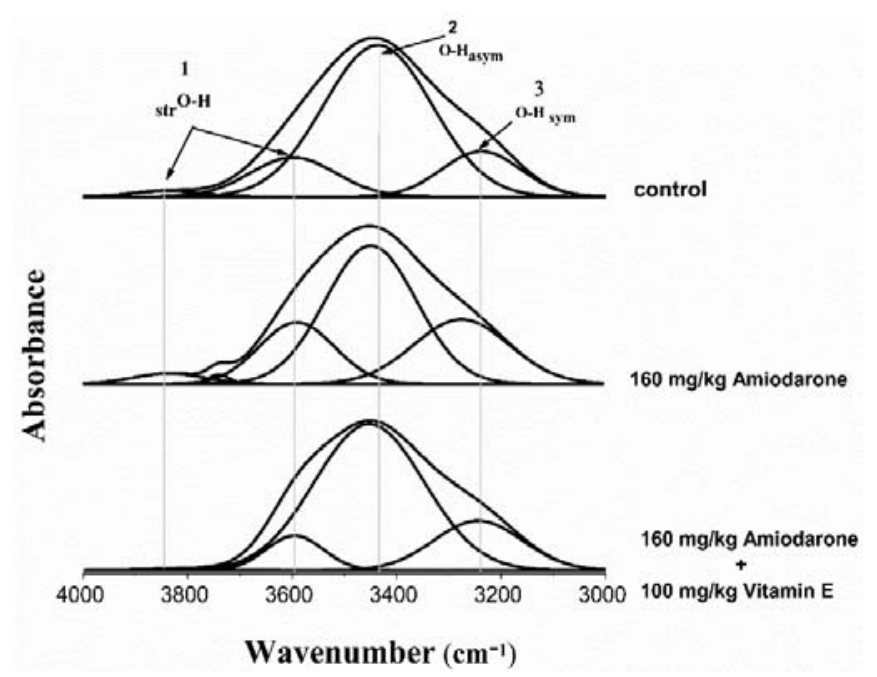

Fig. 2: FTIR spectral region $\left(4000-3000 \mathrm{~cm}^{-1}\right)$ related to $\mathrm{NH}-\mathrm{OH}$ of control optic nerve and all treated groups

Table 1: NHOH region (4000-3000 $\left.\mathrm{cm}^{-1}\right)$ of optic nerve tissue for control and all treated groups

\begin{tabular}{|c|c|c|c|c|c|}
\hline & (1) str $\mathrm{O}-\mathrm{H}$ & & & (2) $0-\mathrm{H}_{\text {asym }}$ & (3) $0-\mathrm{H}_{\text {sym }}$ \\
\hline \multirow[t]{3}{*}{ Control } & $3837 \pm 1$ & & $3598 \pm 1$ & $3435 \pm 2$ & $3238 \pm 4$ \\
\hline & $6 \pm 3$ & & $48 \pm 2$ & $235 \pm 2$ & $51 \pm 7$ \\
\hline & $155 \pm 10$ & & $192 \pm 5$ & $243 \pm 19$ & $179 \pm 4$ \\
\hline \multirow[t]{3}{*}{160 mg/kg Amiodarone } & $3835 \pm 2$ & $3739 \pm 1$ & $3589 \pm 2 \dagger$ & $3447 \pm 2 \dagger$ & $3273 \pm 1 \dagger$ \\
\hline & $11 \pm 3$ & $3 \pm 5$ & $66 \pm 1 \dagger$ & $181 \pm 5 \dagger$ & $39 \pm 7$ \\
\hline & $159 \pm 5$ & $47 \pm 2$ & $170 \pm 5 \dagger$ & $205 \pm 10 \dagger$ & $216 \pm 5 \dagger$ \\
\hline $160 \mathrm{mg} / \mathrm{kg}$ Amiodarone+100 mg/kg & $3829 \pm 7$ & & $3595 \pm 2$ & $3452 \pm 1 \dagger$ & $3243 \pm 3$ \\
\hline \multirow[t]{2}{*}{ Vitamin E } & $2 \pm 3$ & & $28 \pm 6 \dagger$ & $230 \pm 3$ & $63 \pm 6$ \\
\hline & $169 \pm 21$ & & $129 \pm 7 \dagger$ & $247 \pm 11$ & $188 \pm 6$ \\
\hline
\end{tabular}

All data expressed as mean \pm SD. The first line in each cell indicates the vibrational frequency $\left(\mathrm{cm}^{-1}\right)$, the second line reflects the band area, and the third line shows the bandwidth. $\dagger$ Statistically significan, $n=5$

\section{CH region}

Fig. 3 shows the $\mathrm{CH}$ stretching region, which extends from 3000 to $2800 \mathrm{~cm}^{-1}$. The curve enhancement procedure resolved the contour of the control pattern into five components which located at $2985 \pm 2$, $2973 \pm 2,2921 \pm 4,2878 \pm 4$, and $2855 \pm 5 \mathrm{~cm}^{-1}$. The first two components were assigned as asymmetric $\mathrm{CH}_{3}\left(\right.$ asym $\left.\mathrm{CH}_{3}\right)$. The remaining components have belonged to asymmetric $\mathrm{CH}_{2}$ (asym $\mathrm{CH}_{2}$ ), symmetric $\mathrm{CH}_{3}\left({ }_{\text {sym }} \mathrm{CH}_{3}\right)$, and symmetric $\mathrm{CH}_{2}\left({ }_{\text {sym }} \mathrm{CH}_{2}\right)$, respectively. These assignments were performed according to Bozkurt et al. [25]. The changes in the band position and bandwidth of these stretching vibrational bands were listed in table 2 . The contour displays four components in all treated groups. Treatment with amiodarone lead to appear one band corresponding to asym $\mathrm{CH}_{3}$ with a significant decrease $(\mathrm{p}<0.05)$ in its vibrational mode and band area compared to control. Furthermore, the band position of ${ }_{s y m} \mathrm{CH}_{3}$ shifted to a higher frequency, accompanied a significant decrease in its bandwidth and band area. Finally, the band area asym $\mathrm{CH}_{2}$ and ${ }_{\text {sym }} \mathrm{CH}_{2}$ showed a significant increase due to the treatment of amiodarone.

Coadministration of vitamin $\mathrm{E}$ with amiodarone even leads to one band for ${ }_{\text {asym }} \mathrm{CH}_{3}$ but its frequency mimics the control one. In the same context, vitamin $\mathrm{E}$ has a protective effect on ${ }_{\mathrm{sym}} \mathrm{CH}_{3}$ band and its area mimic the control and its effect is in contrast to the effect of amiodarone.

The area ratio of asym $\mathrm{CH}_{2}$ to ${ }_{\mathrm{sym}} \mathrm{CH}_{2}$ was $7.93 \pm 0.03$ in the control group, while the treatment with amiodarone reduced it to $2.51 \pm 0.1$. Coadministration of vitamin $\mathrm{E}$ with amiodarone did not increase this ratio $(2.70 \pm 0.05)$. Further, the area ratio of ${ }_{\text {asym }} \mathrm{CH}_{2}$ to ${ }_{\text {asym }} \mathrm{CH}_{3}$ was elevated from $2.72 \pm 0.4$, in the control group, to $7.30 \pm 0.02$ in the amiodarone-treated group, while the coadministration of vitamin $\mathrm{E}$ returned it to be $3.72 \pm 0.1$. Finally, there was an increase in the absorption intensities of all bands of the $\mathrm{CH}$ stretched region (asym $\mathrm{CH}_{3}$, asym $\mathrm{CH}_{2}$, sym $\mathrm{CH}_{3}$, and sym $\mathrm{CH}_{2}$ ).

Table 2: $\mathrm{CH}$ region $\left(3000-2800 \mathrm{~cm}^{-1}\right)$ of optic nerve tissue for control and all treated groups

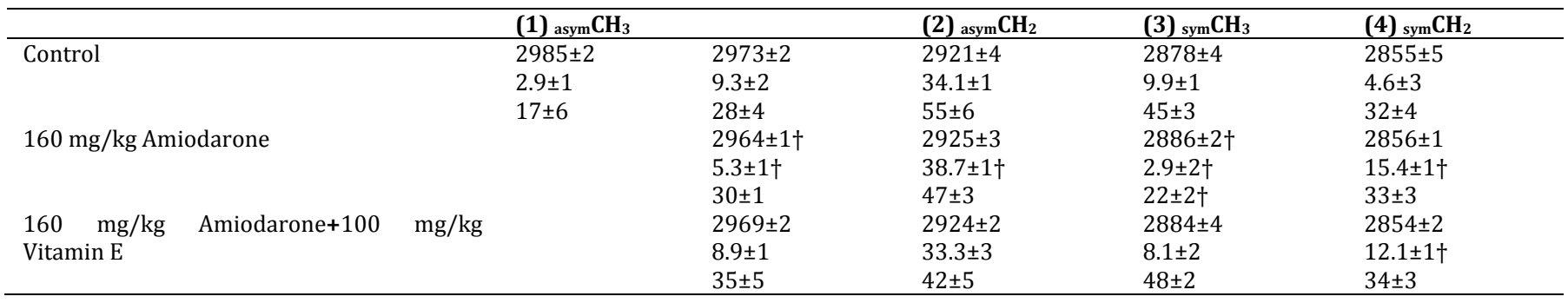

All data expressed as mean \pm SD. First-line in each cell indicates the vibrational frequency $\left(\mathrm{cm}^{-1}\right)$, the second line reflects the band area, and the third line shows the bandwidth. $†$ Statistically significant, $n=5$ 


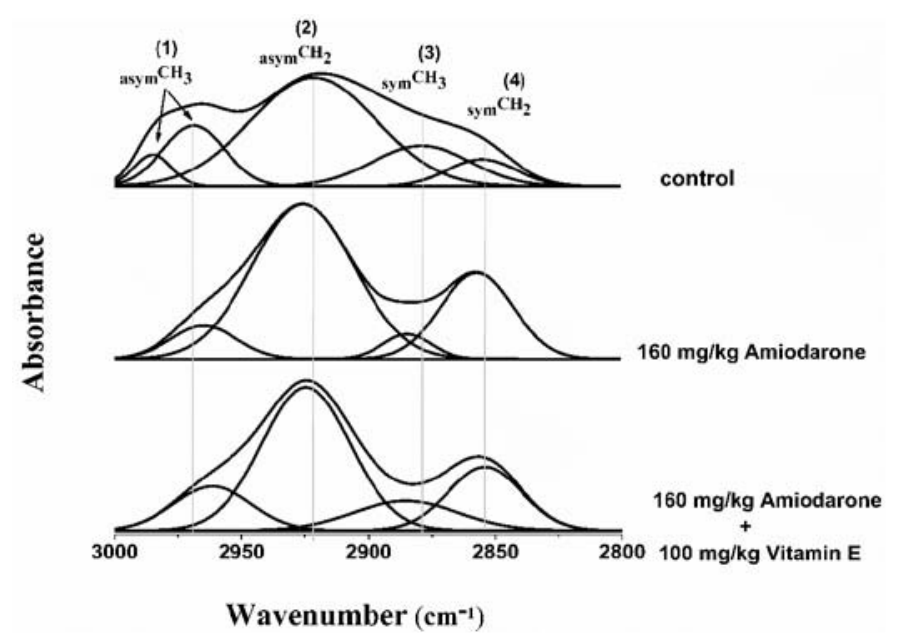

Fig. 3: FTIR spectral region $\left(3000-2800 \mathrm{~cm}^{-1}\right)$ related to $\mathrm{CH}$ region of control optic nerve and all treated groups

\section{Fingerprint region}

Fig. 4 shows the analysis of the fingerprint region $\left(1800-900 \mathrm{~cm}^{-1}\right)$ of the optic nerve tissues. After curve enhancement procedure, the control pattern was resolved into the following bands: $1730 \pm 1$,
$1647 \pm 1,1541 \pm 1,1459 \pm 2,1395 \pm 1,1322 \pm 1,1240 \pm 2,1155 \pm 1$ and $1061 \pm 1 \mathrm{~cm}^{-1}$ which corresponding to Ester $\mathrm{C}=0$, Amide I, Amide II ( $\mathrm{N}=\mathrm{H}_{\text {bend }}$ ), bend $\mathrm{CH}_{2}$, str $\mathrm{COO}_{\text {sym, def }}^{-} \mathrm{CH}_{3}, \mathrm{str}_{2} \mathrm{PO}_{2}^{-}$asym, strCOOCasym, and ${ }_{\text {str }} \mathrm{PO}_{2}^{-}$sym, respectively. These assignments were performed according to Cakmak et al. [26].

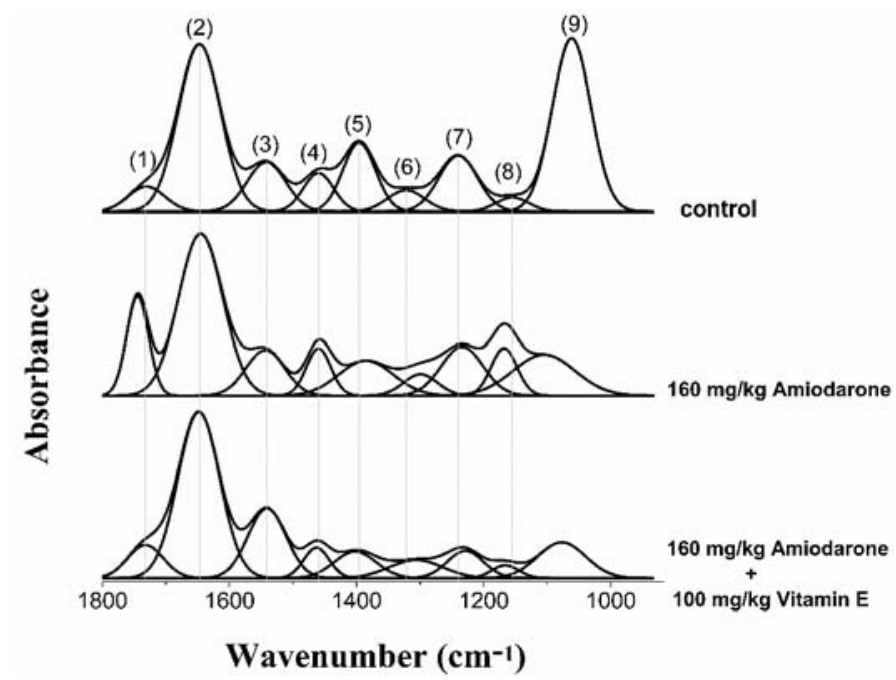

Fig. 4: FTIR spectral region $\left(1800-900 \mathrm{~cm}^{-1}\right)$ related to the fingerprint region of the control optic nerve and all treated groups. (1) Ester $\mathrm{C}=0$,

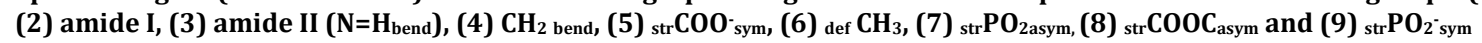

Table 3 listed the changes in band position and bandwidth due to administration of amiodarone either alone or with vitamin E compared to control. From the fig. and the table, it can be noticed that the amiodarone influences the Ester $\mathrm{C}=\mathrm{O}$ vibrational motion. There was an increase in the frequency and band area of this band, accompanied by a reduction in the bandwidth. These changes were improved with co-administrated of vitamin E. Moreover, the bandwidth of bend $\mathrm{CH}_{2}$ mode showed a significant decrease due to amiodarone, even with vitamin E administration. Treatment with amiodarone caused a reduction in the frequency and an increase in the bandwidth of the ${ }_{\text {str }} \mathrm{COO}_{\text {sym }}^{-}$vibrational band. While the coadministration of vitamin E caused a higher shift in frequency and the bandwidth of this band still increased compared to control. There was a reduction in the frequency of ${ }_{\text {def }} \mathrm{CH}_{3}$ and ${ }_{\mathrm{str}} \mathrm{PO}_{2}{ }_{\text {asym }}$ vibrational band in group II, besides the bandwidth of def $\mathrm{CH}_{3}$ decreased. Vitamin E administration with amiodarone caused an elevation in the bandwidth of ${ }_{\text {def }} \mathrm{CH}_{3}$ and a reduction in the band area of ${ }_{\text {str }} \mathrm{PO}_{2}^{-}$asym. At the same time, the decrease in their frequencies existed even with the administration of vitamin $\mathrm{E}$.
On the contrary, the band position of ${ }_{\text {str }} \mathrm{COOC}_{\text {asym }}$ and $\mathrm{str}_{\mathrm{PO}} \mathrm{PO}_{\text {sym }}^{-}$modes were shifted to a higher frequency accompanied by a significant reduction in the bandwidth of ${ }_{\text {str }} \mathrm{COOC}_{\text {asym }}$ mode and an increase in bandwidth of ${ }_{\text {str }} \mathrm{PO}_{2}^{-}$sym mode. Due to amiodarone administration, the band area of ${ }_{\text {str }} \mathrm{COOC}_{\text {asym }}$ and ${ }_{\mathrm{str}} \mathrm{PO}_{2}^{-}$sym increased and decreased, respectively. The uptake of vitamin $\mathrm{E}$ with amiodarone only turned the band area of strCOOCasym to control, but other changes occurred by amiodarone in the frequency and bandwidth of ${ }_{\text {str }} \mathrm{PO}_{2}{ }_{\text {sym }}$ and strCOOC ${ }_{\text {asym }}$ modes still existing.

\section{Amide I}

Fig. 5 shows the spectra of the amide I band, which extended from $1705-1595 \mathrm{~cm}^{-1}$. This band is essential because it provides sensitive information about the protein secondary structure. It is generated due to the stretching vibration of protein amide $\mathrm{I} C=0$. The original amide I band of the control optic nerve was centered at $1648 \pm 2 \mathrm{~cm}^{-1}$. Because of the complexity of this band, we performed a deconvolution after normalization to this band for more details. After deconvolution, the curves were resolved into three 
components that were centered at $1675 \pm 2,1646 \pm 3$ and $1621 \pm 3 \mathrm{~cm}^{-1}$ corresponding to $\beta$-turn, $\alpha$-helix, and $\beta$-sheet, respectively [27]. Table 4 illustrated the area percentage of these components that was changed due to amiodarone administration. The percentage of the $\beta$-turn was significantly increased while the $\alpha$-helix content was reduced. The contents of both components were found to be mimicking the control values when Vitamin E was co-administered with amiodarone.

Table 3: Fingerprint region $\left(1800-900 \mathrm{~cm}^{-1}\right)$ of the optic nerve tissue for control and all treated groups

\begin{tabular}{|c|c|c|c|c|c|c|c|c|c|}
\hline & $\begin{array}{l}\text { (1) } \\
\text { Ester } \mathrm{C}=0\end{array}$ & $\begin{array}{l}\text { (2) } \\
\text { Amide I }\end{array}$ & $\begin{array}{l}\text { (3) } \\
\text { Amide II } \\
\mathrm{N}=\mathrm{H}_{\text {bend }}\end{array}$ & $\begin{array}{l}(4) \\
\text { bend } \mathrm{CH}_{2}\end{array}$ & $\begin{array}{l}\text { (5) } \\
\text { strCOO}_{\text {sym }}\end{array}$ & $\begin{array}{l}\text { (6) } \\
\text { def } \mathrm{CH}_{3}\end{array}$ & $\begin{array}{l}\text { (7) } \\
\text { strPO }{ }_{2}^{-} \text {asym }\end{array}$ & $\begin{array}{l}\text { (8) } \\
\text { strCOOC }\end{array}$ & $\begin{array}{l}\text { (9) } \\
\text { strPO }{ }_{2}^{-} \text {sym }\end{array}$ \\
\hline \multirow[t]{3}{*}{ Control } & $1730 \pm 1$ & $1647 \pm 1$ & $1541 \pm 1$ & $1459 \pm 2$ & $1395 \pm 1$ & $1322 \pm 1$ & $1240 \pm 2$ & $1155 \pm 1$ & $1061 \pm 1$ \\
\hline & $9.9 \pm 2$ & $77 \pm 2$ & $20.8 \pm 1$ & $12.6 \pm 3$ & $20.5 \pm 1$ & $8.6 \pm 2$ & $23.6 \pm 1$ & $4.9 \pm 3$ & $73.6 \pm 1$ \\
\hline & $76 \pm 5$ & $78 \pm 1$ & $71 \pm 3$ & $55 \pm 5$ & $60 \pm 5$ & $68 \pm 2$ & $71 \pm 3$ & $60 \pm 3$ & $71 \pm 1$ \\
\hline $160 \mathrm{mg} / \mathrm{kg}$ & $1744 \pm 3 \dagger$ & $1645 \pm 2$ & $1543 \pm 1$ & $1460 \pm 2$ & $1385 \pm 1 \dagger$ & $1299 \pm 3 \dagger$ & $1234 \pm 1 \dagger$ & $1168 \pm 2 \dagger$ & $1105 \pm 1 \dagger$ \\
\hline \multirow[t]{2}{*}{ Amiodarone } & $23.9 \pm 1 \dagger$ & $78.5 \pm 1$ & $19.3 \pm 2$ & $12.6 \pm 2$ & $24.8 \pm 1 \dagger$ & $8 \pm 1$ & $22.4 \pm 1$ & $13.4 \pm 1 \dagger$ & $27.8 \pm 3 \dagger$ \\
\hline & $40 \pm 3 \dagger$ & $81 \pm 3$ & $71 \pm 2$ & $45 \pm 1 \dagger$ & $100 \pm 1 \dagger$ & $63 \pm 1 \dagger$ & $77 \pm 4$ & $48 \pm 4 \dagger$ & $115 \pm 3 \dagger$ \\
\hline 160 mg/kg Amiodarone & $1731 \pm 3$ & $1648 \pm 3$ & $1540 \pm 1$ & $1462 \pm 2$ & $1402 \pm 1 \dagger$ & $1306 \pm 1 \dagger$ & $1228 \pm 4 \dagger$ & $1165 \pm 1 \dagger$ & $1077 \pm 1 \dagger$ \\
\hline \multirow[t]{2}{*}{ +100 mg/kg Vitamin E } & $13.9 \pm 3$ & $76.4 \pm 1$ & $29.4 \pm 3 \dagger$ & $8.6 \pm 1$ & $12.2 \pm 1 \dagger$ & $10.7 \pm 3$ & $10.9 \pm 3 \dagger$ & $3.8 \pm 2$ & $19.1 \pm 3 \dagger$ \\
\hline & $67 \pm 5$ & $77 \pm 1$ & $70 \pm 1$ & $47 \pm 1 \dagger$ & $77 \pm 4 \dagger$ & $98 \pm 4 \dagger$ & $67 \pm 3$ & $49 \pm 3 \dagger$ & $88 \pm 2 \dagger$ \\
\hline
\end{tabular}

All data expressed as mean \pm SD. First-line in each cell indicates the vibrational frequency $\left(\mathrm{cm}^{-1}\right)$, the second line reflects the band area, and the third line shows the bandwidth. $†$ Statistically significant, $n=5$

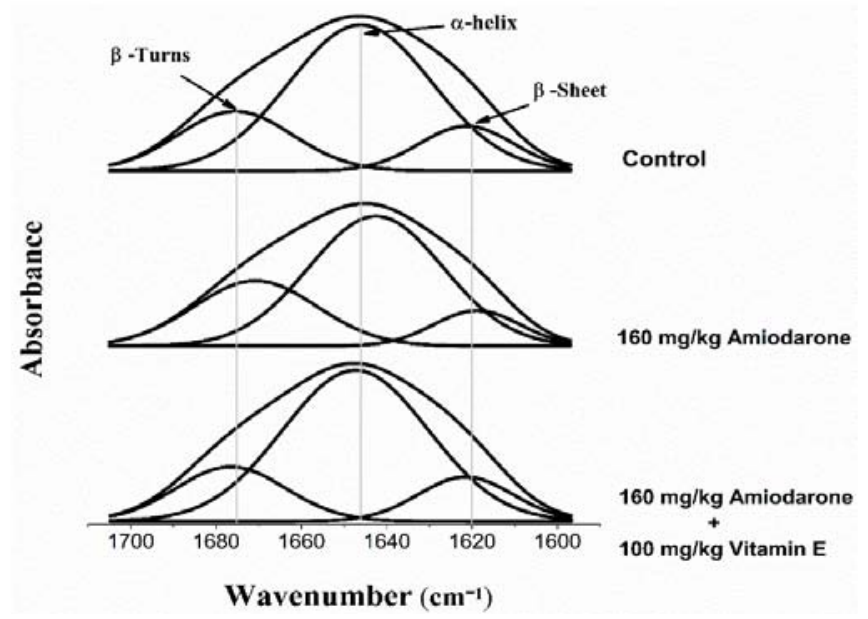

Fig. 5: FTIR spectral region $\left(1700-1600 \mathrm{~cm}^{-1}\right)$ related to the amide I region of the control optic nerve and all treated groups

Table 4: The percentage of protein secondary structure components of the optic nerve of control and treated groups with amiodarone either alone or with vitamin $\mathrm{E}$

\begin{tabular}{|c|c|c|c|}
\hline & $\beta$-turn & $\alpha$-helix & $\beta$-sheet \\
\hline Control & $21.3 \pm 2.3$ & $65.5 \pm 3$ & $13.2 \pm 4$ \\
\hline $160 \mathrm{mg} / \mathrm{kg}$ Amiodarone & $33.2 \pm 1.6 \dagger$ & $55.1 \pm 0.8 \dagger$ & $10.7 \pm 2.7$ \\
\hline $160 \mathrm{mg} / \mathrm{kg}$ Amiodarone $+100 \mathrm{mg} / \mathrm{kg}$ Vitamin E & $18 \pm 2$ & $68.3 \pm 2$ & $13.1 \pm 3$ \\
\hline
\end{tabular}

All data expressed as mean \pm SD, $\uparrow$ Statistically significant, $n=5$

\section{DISCUSSION}

FTIR spectroscopy is increasingly used in the biomedical sciences and it emphasize that the properties of the biological macromolecule, such as structure and conformation of lipids or proteins, degree of lipid order or disorder, and the amount of saturation or unsaturation within lipids, are essential factors in the diagnosis of several physiological disorders.

In the present study, changes observed in the $\mathrm{NHOH}$ bands are considered to be related to proteins, lipids, and polysaccharides, not from water because, during the FTIR preparations, water was carefully removed from the sample. Therefore, the changes observed due to amiodarone administration, especially in strO-H vibrational mode, referred to form a new type of hydrogen bonds with the different structural states in the protein or the other constituents of optic nerve tissue. The increase in frequencies of vibrational modes $\mathrm{O}-\mathrm{H}_{\text {asym }}$ and $\mathrm{O}-\mathrm{H}_{\text {sym }}$ also supports the above findings of the formation of hydrogen bonds which were likely to be the connection bond between the drug and the optic nerve tissue components. On the other hand, the coadministration of vitamin $\mathrm{E}$ with amiodarone improves these changes, especially in the ${ }_{\mathrm{str}} \mathrm{O}-\mathrm{H}$ and $\mathrm{O}-\mathrm{H}_{\text {sym }}$ bands. In the $\mathrm{CH}$ stretched bands, asym $\mathrm{CH}_{2}$ and ${ }_{\text {sym }} \mathrm{CH}_{2}$ were considered essential vibrational bands because of their use in lipid description. Since the change in the intensity or/and area of the band belongs to a change in the concentration of the functional group related to this band; hence the increases in the intensity and area of the asym $\mathrm{CH}_{2}$ and ${ }_{\text {sym }} \mathrm{CH}_{2}$ band due to amiodarone administration indicates an increase in the total lipid content and acyl chains composition of optic nerve tissue. This increase in the lipid content is related to the disturbance of the lipid metabolism $[28,29]$. 
In the FTIR spectrum, the degree of disorder within the lipid hydrocarbon chain can be derived from the ratio between the area of asym $\mathrm{CH}_{2}$ to ${ }_{\text {sym }} \mathrm{CH}_{2}$ bands [27]. Indeed, there was a reduction in this ratio when the amiodaron administration, implying that the hydrocarbon chain of optic nerve lipids became more ordered even with vitamin E intake; the hydrocarbon chain is still more ordered [30]. Moreover, the lengths of hydrocarbon chains can be predicted from the ratio between the area of asym $\mathrm{CH}_{2}$ to asymCH 3 bands [25]. There was an increase in this ratio due to amiodarone treatment, indicating that the hydrocarbon chain of optic nerve lipid became longer compared to the control group, while the intake of vitamin E with amiodarone removed this effect. These findings were confirmed by the results obtained from the fingerprint region since the observed increase in the intensity and the band area of Ester $\mathrm{C}=0$ mode indicates an increase in ester group content in the optic nerve tissue [31]. Besides, the increase in the band area of the ${ }_{\text {str }} \mathrm{COO}_{\text {sym }}^{-}$mode indicates an increase in the optic nerve fatty acids content [28].

The changes observed in Ester $\mathrm{C}=0$, str $\mathrm{COOC}_{\text {asym, asym }} \mathrm{PO}_{2}$ and ${ }_{\text {sym }} \mathrm{PO}_{2}$ was a sign of alter in the structure and conformation of lipids due to amiodarone administration because the absorption frequency of the Ester $\mathrm{C}=\mathrm{O}$ band reflects the length of the fatty acid chain, the area of the ${ }_{\text {str }} \mathrm{COOC}_{\text {asym }}$ vibrational band belongs to lipids ester and asym $\mathrm{PO}_{2}$, sym $\mathrm{PO}_{2}$ bands belong to the phosphodiester backbone of phospholipids [27].

Since above fifty percent of the optic nerve tissue constitutes lipid, especially phospholipid, any change in the lipid structure or conformation induces an alteration in the physiological and pathological state of the optic nerve [32].

The observed increase in the total lipid content, fatty acid, and hydrocarbon chain length associated with amiodarone administration might be linked to mitochondrial dysfunction, specifically inhibition of mitochondrial fatty acid oxidation induced by amiodarone. This, in turn, results in an accumulation of lipid in the optic nerve tissue [33]. Previous studies stated that amiodarone had induced inhibition in the fatty acid oxidative enzymes [34, 35]. The other mechanism that might explain this elevation in lipid content is that amiodarone can induce lysosomal phospholipidosis, inhibition of lysosomal phospholipases, which leads to an abnormal degradation of phospholipids causing intracytoplasmic accumulation of degraded phospholipids [36].

Amide I absorption is a result of protein $\mathrm{C}=0$ stretching vibrations and is sensitive to protein conformation. It is mainly being used for the changes in the secondary structures of proteins and polypeptides. Hence, the reduction in the $\alpha$-helix and elevation in the $\beta$-turn contents associated with amiodarone indicate that the drug administration changed the solubility and folding of the optic nerve protein [37].

Vitamins intake is seen in research to be useful for individuals along with cardiovascular disease [38]. Vitamin E supplementation partially improved the optic nerve spectral analysis changes due to amiodarone injection in rabbit's since vitamin $\mathrm{E}$ could decrease lysosomal phospholipidosis and amiodarone toxicity [7, 39]. Also, it has a significant inhibition effect in forming the thiobarbituric acid reactive substance that is used to determine the free radical mediated-lipid peroxidation in homogenous tissue.

\section{CONCLUSION}

Our results revealed that the short-term administration of amiodarone caused a significant alteration in the structure and conformation of the optic nerve tissue contents, especially the lipid contents and variation in the protein secondary structure of the optic nerve. Vitamin E intake with amiodarone turns many of these changes induced by amiodarone to normal levels, which make it a good supplement for amiodarone users.

\section{FUNDING}

Nil

\section{AUTHORS CONTRIBUTIONS}

All the authors contributed equally.

\section{CONFLICT OF INTERESTS}

Declared none

\section{REFERENCES}

1. Arevalo HJ, Vadakkumpadan F, Guallar E, Jebb A, Malamas P, Wu KC, Trayanova NA. Arrhythmia risk stratification of patients after myocardial infarction using personalized heart models. Nat Commun. 2016;7(1):11437. doi: 10.1038/ncomms11437, PMID 27164184.

2. Shiraishi A, Hayashi Y, Ogimoto A, Ohashi Y. In vivo confocal microscopic observations of vortex keratopathy in patients with Amiodarone-induced Keratopathy and Fabry disease. Kegawa Y J Ophthalmol. 2018. doi: 10.1155/2018/5315137

3. Punnam SR, Goyal SK, Kotaru VP, Pachika AR, Abela GS, Thakur RK. Amiodarone- a 'broad spectrum' antiarrhythmic drug. Cardiovasc Hematol Disord Drug Targets. 2010;10(1):73-81. doi: 10.2174/187152910790780032, PMID 20041841.

4. Rusinova R, Koeppe RE, Andersen OS. A general mechanism for drug promiscuity: studies with amiodarone and other antiarrhythmics. J Gen Physiol. 2015;146(6):463-75. doi: 10.1085/jgp.201511470, PMID 26573624.

5. Wang AG, Cheng HC. Amiodarone-associated optic neuropathy: clinical review. Neuro-Ophthalmology. 2017;41(2):55-8. doi: 10.1080/01658107.2016.1247461, PMID 28348626.

6. Florek JB, Girzadas D. Amiodarone. StatPearls. Available from: https://www.ncbi.nlm.nih.gov/books/NBK482154. [Last accessed on 23 Aug 2021]

7. Zidan RA. Effect of long-term administration of amiodarone on rat lung and the possible protective role of vitamin E. Egypt J Histol. 2011;34(1):117-28. doi: 10.1097/ 01.EHX. 0000395190.66459 .04 .

8. Kim G, Choi HK, Lee H, Moon KS, Oh JH, Lee J, Shin JG, Kim DH. Increased hepatic acylcarnitines after oral administration of amiodarone in rats. J Appl Toxicol. 2020 Jul;40(7):1004-13. doi: 10.1002/jat.3960, PMID 32084307.

9. Morales AI, Barata JD, Bruges M, Arevalo MA, Gonzalez de Buitrago JM, Palma P, Branco P, Perez Barriocanal F. Acute renal toxic effect of amiodarone in rats. Pharmacol Toxicol. 2003;92(1):39-42. doi: 10.1034/j.1600-0773.2003.920107.x, PMID 12710596.

10. Maqdasy S, Benichou T, Dallel S, Roche B, Desbiez F, Montanier $\mathrm{N}$, Batisse-Lignier $\mathrm{M}$, Tauveron I. Issues in amiodarone-induced thyrotoxicosis: update and review of the literature. Ann Endocrinol (Paris). 2019;80(1):54-60. doi: 10.1016/j.ando.2018.05.001, PMID 30236455.

11. Atıcı A, Asoglu R, Barman HA, Sahin I. Amiodarone-related blue-gray skin discoloration. Anatol J Cardiol. 2019;21(5):5011-2. doi: 10.14744/AnatolJCardiol.2019.84890. PMID 31062764.

12. Alshehri M, Joury A. Ocular adverse effects of amiodarone: a systematic review of case reports. Optom Vis Sci. 2020;97(7):536-42. doi: 10.1097/OPX.0000000000001534, PMID 32697562.

13. Serviddio G, Bellanti F, Giudetti AM, Gnoni GV, Capitanio N, Tamborra R, Romano AD, Quinto M, Blonda M, Vendemiale G, Altomare E. Mitochondrial oxidative stress and respiratory chain dysfunction account for liver toxicity during amiodarone but not dronedarone administration. Free Radical Biol Med. 2011;51(12):2234-42. 10.1016/j.freeradbiomed.2011.09.004, PMID 21971348.

14. Mostafa M, EL-Shafei M. Can L-carnitine protect against amiodarone-induced optic neuropathy in rabbits? The Egypt J Anat. 2011;34(1):63-78. doi: 10.21608/ejana.2011.3653.

15. Martinez LoPez-Portillo MA, Martinez Gamero BO, Mohamed Noriega J, Cavazos Adame MH, Mohamed Hamsho MJ. Behaviour of disc oedema during and after amiodarone optic neuropathy: case report. J Clin Diagn Res. 2014;8(4):VD04-5. doi: 10.7860/JCDR/2014/8254.4262. PMID 24959500.

16. Arcani R, Pellerey M, Rouby F, Gobin N, Scapin J, Chagny M, Arnould T, Ambrosi P, Gayet S, Micallef J, Villani P, Daumas A. Amiodarone-induced optic neuropathy: A rare side effect. Rev Med Interne. 2019 Dec;40(12):826-30. doi: 10.1016/ j.revmed.2019.09.001, PMID 31561935. 
17. Cheng HC, Yeh HJ, Huang N, Chou YJ, Yen MY, Wang AG. Amiodarone-associated optic neuropathy: a nationwide study. Ophthalmology. 2015;122(12):2553-9. doi: 10.1016/ j.ophtha.2015.08.022, PMID 26391464.

18. Wang AG. Emergency neuro-ophthalmology, emergency neuroophthalmology; 2018.

19. Jiang Q. Natural forms of vitamin E: metabolism, antioxidant, and anti-inflammatory activities and their role in disease prevention and therapy. Free Radic Biol Med. 2014;72:76-90. doi: 10.1016/j.freeradbiomed.2014.03.035, PMID 24704972.

20. Agoston M, Orsi F, Feher E, Hagymasi K, Orosz Z, Blazovics A, Feher J, Vereckei A. Silymarin and vitamin E reduce amiodarone-induced lysosomal phospholipidosis in rats. Toxicology. 2003;190(3):231-41. doi: 10.1016/s0300483x(03)00188-4, PMID 12927377.

21. Zaki MSA, Eid RA. Role of vitamin-E on rat liver-amiodarone: an ultrastructural study. Saudi J Gastroenterol. 2009;15(2):10410. doi: 10.4103/1319-3767.48967, PMID 19568574.

22. Hartog M, Zhu Y, Lawrence D, Herron B, Ding X. Influence of hepatic P450-mediated amiodarone metabolism on amiodarone-induced pulmonary toxicity. FASEB J. 2013;27(S1):1107-14. doi: 10.1096/fasebj.27.1_supplement.1107.14.

23. Aleti R, Baratam SR, Jagirapu B, Kudamala S. Formulation and evaluation of metformin hydrochloride and gliclazide sustained release bilayer tablets: combination therapy in the management of diabetes. Int J App Pharm. 2021;13(5):343-50. doi: 10.22159/ijap.2021v13i5.41339.

24. Dovbeshko GI, Gridina NY, Kruglova EB, Pashchuk OP. FTIR spectroscopy studies of nucleic acid damage. Talanta. 2000;53(1):233-46. doi: 10.1016/s0039-9140(00)00462-8, PMID 18968108.

25. Bozkurt O, Severcan M, Severcan F. Diabetes induces compositional, structural and functional alterations on rat skeletal soleus muscle revealed by FTIR spectroscopy: A comparative study with EDL muscle. Analyst. 2010;135(12):3110-9. doi: 10.1039/c0an00542h, PMID 20967384.

26. Cakmak G, Miller LM, Zorlu F, Severcan F. Amifostine, a radioprotectant agent, protects rat brain tissue lipids against ionizing radiation-induced damage: an FTIR microspectroscopic imaging study. Arch Biochem Biophys. 2012 Apr 15;520(2):67-73. doi: 10.1016/j.abb.2012.02.012, PMID 22402174.

27. Mahmoud SS, ElAbrak ES, Aly MA, Ali EM. Oculohypotensive effects of various acetozolamide nano preparation for topical treatment of animal model-induced glaucoma and their impact on optic nerve. PLOS ONE. 2019;14(2):e0212588. doi: 10.1371/journal.pone.0212588, PMID 30789966.

28. Simsek Ozek N, Sara Y, Onur R, Severcan F. Low dose simvastatin induces compositional, structural and dynamic changes in rat skeletal extensor digitorum longus muscle tissue. Biosci Rep. 2009;30(1):41-50. doi: 10.1042/ BSR20080150, PMID 19228123.
29. McCarthy TC, Pollak PT, Hanniman EA, Sinal CJ. Disruption of hepatic lipid homeostasis in mice after amiodarone treatment is associated with peroxisome proliferator-activated receptor- $\alpha$ target gene activation. J Pharmacol Exp Ther. 2004;311(3):86473. doi: 10.1124/jpet.104.072785, PMID 15265979.

30. Chatelain P, Ferreira J, Laruel R, Ruysschaert JM. Amiodarone induced modifications of the phospholipid physical state. A fluorescence polarization study. Biochem Pharmacol. 1986 Sep 15;35(18):3007-13. doi: 10.1016/0006-2952(86)90379-5, PMID 3753514.

31. Dritsa V Theophanides T. editor. FTIR spectroscopy in medicine. Infrared Spectroscopy Life and biomaterial Sciences. Rijeka, Croatia: Intech Publications; 2012. p. 271-88.

32. Acar N, Berdeaux O, Gregoire S, Cabaret S, Martine L, Gain P, Thuret G, Creuzot Garcher CP, Bron AM, Bretillon L. Lipid composition of the human eye: are red blood cells a good mirror of retinal and optic nerve fatty acids? PLOS ONE 2012;7(4):e35102. doi: 10.1371/journal.pone.0035102, PMID 22496896.

33. Begriche K, Massart J, Robin MA, Borgne Sanchez A, Fromenty B. Drug-induced toxicity on mitochondria and lipid metabolism: mechanistic diversity and deleterious consequences for the liver. J Hepatol. 2011 Apr;54(4):773-94. doi: 10.1016/j.jhep.2010.11.006, PMID 21145849.

34. Fromenty B, Fisch C, Labbe G, Degott C, Deschamps D, Berson A, Letteron P, Pessayre D. Amiodarone inhibits the mitochondrial beta-oxidation of fatty acids and produces microvesicular steatosis of the liver in mice. J Pharmacol Exp Ther. 1990 Dec;255(3):1371-6. PMID 2124623.

35. Fromenty B, Pessayre D. Inhibition of mitochondrial betaoxidation as a mechanism of hepatotoxicity. Pharmacol Ther. 1995;67(1):101-54. doi: 10.1016/0163-7258(95)00012-6, PMID 7494860.

36. Jiang H, Passarelli MK, Munro PM, Kilburn MR, West A, Dollery CT, Gilmore IS, Rakowska PD. High-resolution sub-cellular imaging by correlative NanoSIMS and electron microscopy of amiodarone internalization by lung macrophages as evidence for drug-induced phospholipidosis. Chem Commun (Camb). 2017 Jan 26;53(9):1506-9. doi: 10.1039/c6cc08549k, PMID 28085162.

37. Sherif MS, Mervat AA, Eman AM. Infrared spectroscopic investigation of erythrocyte membrane-smoke interactions due to chronic cigarette smoking. Gen Physiol Biophys. 2017 Jul;36(3):273-80. doi: 10.4149/gpb_2016047, PMID 28471349.

38. Khairnar N, Pingale P, Amrutkar S. Role of micronutrients in heart diseases. Int J Curr Pharm Sci 2021 Sep;13(5):1-5. doi: 10.22159/ijcpr.2021v13i5.1880.

39. Shatoor AS, Zaki MS, Eid RA, Sayed-Ahmad MA. Ultrastructural changes in Rat"s atrial cardiomyocytes after short-term administration of amiodarone and possible protective role of vitamin E. J Clin Med Res. 2012 Jun;4(3):190-6. doi: 10.4021/jocmr909w, PMID 22719805. 